\title{
Characterization of Soil Water Repellency for Agricultural Farms with Different Soil Management Systems
}

\author{
Wijewardana Y.N.S. ${ }^{*}$, Kuroki H..$^{2}$, Kawamoto K. ${ }^{2}$, Hiradate S. ${ }^{3}$, Muller K. ${ }^{4}$, \\ Clothier B.E. ${ }^{4}$, Mason K. ${ }^{4}$, Simpson R. ${ }^{4}$, and Komatsu T. ${ }^{2}$ \\ ${ }^{1}$ Uva Wellassa University, Sri Lanka \\ ${ }^{2}$ Saitama University, Japan \\ ${ }^{3}$ Institute for Agro-Environmental Sciences, National Agriculture and Food Research Organization, \\ Japan \\ ${ }^{4}$ The New Zealand Institute for Plant and Food Research Limited, New Zealand \\ *senanipdn@gmail.com
}

\begin{abstract}
Soil water repellency (SWR) is a phenomenon that can reduce water infiltration into the soil. Generally, the quantity and quality of soil organic matter and the soil moisture content will govern the severity of SWR. The objectives of this study were (i) to characterize SWR for greenhouse and grassland soils using the water drop penetration time (WDPT) test and (ii) to find relationships among the field and laboratory WDPT (WDPTfield and WDPTlab), and the SDM measurements. Two farms that produce vegetables in greenhouses from Japan (Mizuho farm, Miki city, Hyogo) and a beef farm from New Zealand (Tihoi, near Taupo, Waikato) under perennial mixed grass (Lolium perenne L. and Trifolium repens L.) were selected as experimental sites. The New Zealand hillslope site was located on an Andosol. In the greenhouses at the two Japanese sites, vegetables such as spinach (Spinacia oleracea) and spring onion (Allium spp.) were grown on fine-textured Haplic Brown Lowland Soil. The latter soils were fertilized once a season with farm-made compost. Water repellency was measured along a rectangular grid and selected transects. The WDPT was measured using micro-syringe water droplets $(50 \mu \mathrm{L})$ with five replicates. The WDPTlab and SDM were measured using repacked soil cores. The values of WDPTfield varied widely from non-repellent to extreme SWR. The water repellent soil has observed for grassland soils at $\mathrm{pF}(=\log [-\psi]$, where $\psi$ is the soil water matric potential in centimeters of $\mathrm{H}_{2} \mathrm{O}$ ) of $3.2-4.4$ range. The measured WDPTlab showed a linear relationship with the measured SDM $\left(r^{2}=0.80\right)$.
\end{abstract}

Keywords: Soil water repellency, Water drop penetration time, Soil organic matter, Soil moisture 